\title{
The impact of resolution on ship plume simulations with $\mathrm{NO}_{\mathrm{x}}$ chemistry
}

\author{
C. L. Charlton-Perez ${ }^{1,2}$, M. J. Evans ${ }^{1}$, J. H. Marsham ${ }^{1}$, and J. G. Esler ${ }^{2}$ \\ ${ }^{1}$ Institute for Climate and Atmospheric Science, School of Earth and Environment, University of Leeds, Leeds, UK \\ ${ }^{2}$ Department of Mathematics, University College London, London, UK
}

Received: 25 January 2009 - Published in Atmos. Chem. Phys. Discuss.: 31 March 2009

Revised: 28 July 2009 - Accepted: 31 July 2009 - Published: 9 October 2009

\begin{abstract}
A high resolution chemical transport model of the marine boundary layer is designed in order to investigate the detailed chemical evolution of a ship plume in a tropical location. To estimate systematic errors due to finite model resolution, otherwise identical simulations are run at a range of model resolutions. Notably, to obtain comparable plumes in the different simulations, it is found necessary to use an advection scheme consistent with the Large Eddy Model representation of sub-grid winds for those simulations with degraded resolution. Our simulations show that $\mathrm{OH}$ concentration, $\mathrm{NO}_{\mathrm{x}}$ lifetime and ozone production efficiency of the model change by $8 \%, 32 \%$ and $31 \%$ respectively between the highest $(200 \mathrm{~m} \times 200 \mathrm{~m} \times 40 \mathrm{~m})$ and lowest resolution $(9600 \mathrm{~m} \times 9600 \mathrm{~m} \times 1920 \mathrm{~m})$ simulations. Interpolating to the resolution of a typical global composition transport model $\left(\mathrm{CTM}, 5^{\circ} \times 5^{\circ}\right)$, suggests that a CTM overestimates $\mathrm{OH}, \mathrm{NO}_{\mathrm{x}}$ lifetime and ozone production efficiency by approximately $15 \%, 55 \%$ and $59 \%$ respectively. For the first time, by explicitly degrading the model spatial resolution we show that there is a significant reduction in model skill in accurately simulating the aforementioned quantities due to the coarse resolution of these CTMs and the non-linear nature of atmospheric chemistry. These results are significant for the assessment and forecasting of the climate impact of ship $\mathrm{NO}_{\mathrm{x}}$ and indicate that for realistic representation of ship plume emissions in CTMs, some suitable parametrisation is necessary at current global model resolutions.
\end{abstract}

Correspondence to:

C. L. Charlton-Perez

(cristina.l.perez@gmail.com)

\section{Introduction}

Oxides of nitrogen $\left(\mathrm{NO}_{\mathrm{x}}\right)$ play a central role in determining the composition of the atmosphere. A significant source of $\mathrm{NO}_{\mathrm{x}}$ is from shipping; however, its inclusion in global atmospheric composition transport models (CTMs) leads to a significant reduction in model skill in simulating the composition of the marine boundary layer (MBL). International shipping consumes $16 \%$ of the total fuel for all traffic (road and aviation included) with the ocean-going fleet emitting approximately 9.2 times the $\mathrm{NO}_{\mathrm{x}}$ of aviation traffic (Eyring et al., 2005b). Increased industrialization and globalization suggest that ship emissions will continue to grow at around $3 \% \mathrm{yr}^{-1}$ (Entec, 2002). By 2050, ship-emitted $\mathrm{NO}_{\mathrm{x}}$ could exceed that emitted by present-day road traffic, if the extrapolation is based on an emissions scenario corresponding to high GDP growth (Eyring et al., 2005a).

The high temperature combustion in ship engines leads to emissions high in $\mathrm{NO}_{\mathrm{x}}$, but low in other photo-pollutants such as carbon monoxide (CO) and volatile organic compounds (VOCs) relative to other sources. Corbett and Koehler (2003) found the $\mathrm{NO}_{\mathrm{x}}$ emissions from shipping to be $6.87 \mathrm{Tg} \mathrm{N} \mathrm{yr}^{-1}$ with a 5 th to 95 th percentile spread of 6.19 to $9.15 \mathrm{Tg} \mathrm{N} \mathrm{yr}^{-1}$. This can be compared to a global anthropogenic $\mathrm{NO}_{\mathrm{x}}$ emission of $33 \mathrm{Tg} \mathrm{N} \mathrm{yr}{ }^{-1}$ and emissions from all sources of $52 \mathrm{Tg} \mathrm{N} \mathrm{yr}^{-1}$ (IPCC, 2007). Whereas most $\mathrm{NO}_{\mathrm{x}}$ sources are to be found over land, emissions from shipping occur within the MBL and therefore constitute the only large primary $\mathrm{NO}_{\mathrm{x}}$ source in these regions.

Endresen et al. (2003) found significant perturbations to $\mathrm{NO}_{\mathrm{x}}, \mathrm{NO}_{\mathrm{y}}$ and $\mathrm{O}_{3}$ within the MBL due to ship emissions and then investigated this impact on the climate system. Their model calculations indicated that the resulting increase in ozone $\left(\mathrm{O}_{3}\right)$ leads to an increase in radiative forcing since pre-industrial times of $0.029 \mathrm{~W} \mathrm{~m}^{-2}$. They also found that

Published by Copernicus Publications on behalf of the European Geosciences Union. 
the global increase in $\mathrm{OH}$ concentrations leads to a decrease in methane $\left(\mathrm{CH}_{4}\right)$ concentrations that also has a radiative impact and calculate this to be $-0.020 \mathrm{~W} \mathrm{~m}^{-2}$ since preindustrial times. Thus, in their study the changes in radiative forcing since pre-industrial times due to emissions from ships are estimated to be $8.2 \%$ for $\mathrm{O}_{3}$ and $-4.2 \%$ for $\mathrm{CH}_{4}$ (Endresen et al., 2003).

Remarkably, tropospheric reactive trace gases $\mathrm{O}_{3}$ and $\mathrm{CH}_{4}$ together contribute approximately half as much towards positive global radiative forcing as carbon dioxide $\left(\mathrm{CO}_{2}\right)$ (IPCC, 2007). Emission of oxides of nitrogen $\left(\mathrm{NO}_{\mathrm{x}}\right)$ plays a crucial role in determining the sources and sinks of $\mathrm{O}_{3}$ and the lifetime of $\mathrm{CH}_{4}$ (Logan, 1985). Therefore, understanding the source and chemical fate of $\mathrm{NO}_{\mathrm{x}}$ is key to understanding the global chemistry-climate system.

Understanding the processes controlling the composition of the MBL and its photochemistry is of central importance to the chemistry-climate system. Over $50 \%$ of $\mathrm{CH}_{4}$ is destroyed within the MBL (Lawrence et al., 2001) and the MBL constitutes a large sink for $\mathrm{O}_{3}$. Thus, although far from pollution sources, the MBL plays an important role in removing climatically important trace gases.

Previous studies with global CTMs have found that ship emissions cause large perturbations in the composition of the MBL. Lawrence and Crutzen (1999) found that when ship $\mathrm{NO}_{\mathrm{x}}$ emissions were included in their global CTM, surface $\mathrm{NO}_{\mathrm{x}}$ concentrations increased twofold over much of the northern Atlantic, Pacific and Indian Oceans; $\mathrm{O}_{3}$ concentrations increased over the central North Atlantic and Pacific Oceans by greater than a factor of 2; and $\mathrm{OH}$ increased by more than $20 \%$ over similar areas. Even greater model increases of $\mathrm{NO}_{\mathrm{x}}, \mathrm{O}_{3}$ and $\mathrm{OH}$ were found when the study focused on shipping lanes away from the coasts. Kasibhatla et al. (2000) found the inclusion of ship emissions of $\mathrm{NO}_{\mathrm{x}}$ caused a seven-fold increase in the modelled $\mathrm{NO}_{\mathrm{x}}$ concentration in the North Atlantic MBL. In an independent study, Davis et al. (2001) also demonstrated that including ship emissions in a CTM can overestimate the observed median $\mathrm{NO}_{\mathrm{x}}$ values by 2.5 to 4 times even when accounting for model bias. While Lawrence and Crutzen (1999) did have evidence that models could approximate observed NO concentrations from the OCTA-2 campaign, they stated that at the time of their study observations were still too sparse to draw a "clear picture of the actual average $\mathrm{MBL} \mathrm{NO}_{\mathrm{x}}$ levels in the shipping lanes." Both later studies, Kasibhatla et al. (2000) and Davis et al. (2001), had access to a larger set of observational data for their comparisons.

The apparent errors in model chemical budgets associated with ship emissions, including significant overestimate of ozone production, have been hypothesized to be due to model resolution effects. In a coarse resolution model, chemical mixing ratios near emissions sites are instantaneously homogenized within the volume of a model grid-box. There are many studies which replace the instantaneous dilution in a model by some form of plume dynamics and discover very different outcomes in the chemical evolution of the boundary layer. For example, von Glasgow et al. (2003) found that $\mathrm{NO}_{\mathrm{x}}$ lifetime is significantly decreased in the plume relative to the background air due to enhanced $\mathrm{OH}$ concentrations in the plume. Song et al. (2003) examined the evolution of a plume mixing with the ambient air at different latitudes and under day vs. night conditions and diagnosed differences in $\mathrm{NO}_{\mathrm{x}}$ lifetime values up to a factor of 10 between the background and the plume air. It is well-established that, due to the nonlinearity of $\mathrm{O}_{\mathrm{x}}-\mathrm{HO}_{\mathrm{x}}-\mathrm{NO}_{\mathrm{x}}$ chemistry, artificially rapid mixing in instantaneous dilution scenarios can lead to systematic changes in net radical concentrations, and consequently to errors in the tendencies of many radiatively active gases including ozone (Chatfield and Delaney, 1990; Liang and Jacobson, 2000).

The existence of a mechanism leading to the overestimation of ozone production rates in coarse resolution models is apparent if one considers the two distinct chemical regimes that exist near any localised source of $\mathrm{NO}_{\mathrm{x}}$, including ship plumes. At the core of the plume near the source, $\mathrm{NO}_{\mathrm{x}}$ concentrations are high, and the ozone production efficiency $(\mathrm{OPE})$, or number of ozone molecules produced per $\mathrm{NO}_{\mathrm{x}}$ molecule destroyed, is known to be low (Liu et al., 1987). Further from the source, where the emitted $\mathrm{NO}_{\mathrm{x}}$ has been diluted by clean MBL air, the OPE may be many times higher. Generally, clean MBL air has high OPE and a low concentration of $\mathrm{NO}_{\mathrm{x}}$ leading to little $\mathrm{O}_{3}$ production. However, the more rapid the mixing experienced by the plume, the less time a typical $\mathrm{NO}_{\mathrm{x}}$ molecule spends in the low OPE regime, and the greater its probability of reaching the high efficiency regime before it is destroyed. If a plume is poorly resolved due to coarse model resolution, the associated artificial mixing will therefore ensure that the average OPE is higher. Esler et al. (2004) have shown the degradation of CTM model fields, from a horizontal resolution of $2.75^{\circ} \times 2.75^{\circ}$ (T21) to $5.5^{\circ} \times 5.5^{\circ}(\mathrm{T} 42)$, leads to a systematic increase of $5-10 \%$ in OPE throughout the troposphere. In shipping lanes where strong gradients of $\mathrm{NO}_{\mathrm{x}}$ exist at the edges of ship plumes, the resolution effect might be expected to be greater, although the details must depend on the details of the emissions and the typical "plume dilution scenario" (Esler, 2003). In a recent study of idealised ship plume models, by Franke et al. (2008), an instantaneous dilution scenario is compared with a Gaussian plume model. Ozone production was found to be overestimated by a factor of three in the instantaneous dilution model unless the sub-grid plume dynamics were accounted for by means of a parameterisation. Establishing whether or not the resolution effect can partially account for the erroneous representation of ship emission effects in CTMs will be one of the main objectives of this study.

However, there may be other explanations for the CTM failure: emissions may be lower than anticipated, heterogeneous chemistry in the plume may remove the $\mathrm{NO}_{\mathrm{x}}$ or halogen chemistry within the MBL may lead to enhanced $\mathrm{O}_{3}$ and $\mathrm{NO}_{\mathrm{x}}$ loss rates and enhanced rates of removal. A 
multi-model study of the global impact of shipping on $\mathrm{NO}_{\mathrm{x}}$ and $\mathrm{O}_{3}$ found that the estimated uncertainty resulting from a combination of the uncertainties in ship emission totals, global distribution of ship emissions and the neglect of ship plume dispersion was greater than the uncertainties resulting from using the different models (Eyring et al., 2007). Therefore, the ability of resolution to explain the perceived failure of global models to simulate ship $\mathrm{NO}_{\mathrm{x}}$ emissions should and can be tested fully within a single model.

Ship emissions in global 3-D CTMs are parameterized, if they are included, and typically cause models to significantly overestimate $\mathrm{NO}_{\mathrm{x}}$ and $\mathrm{O}_{3}$ in the MBL (Kasibhatla et al., 2000; Davis et al., 2001; Endresen et al., 2003). This overestimate is usually partially attributed to the combination of coarse spatial resolution and the non-linear nature of the $\mathrm{O}_{\mathrm{x}}-\mathrm{HO}_{\mathrm{x}}-\mathrm{NO}_{\mathrm{x}}$ chemistry (Song et al., 2003). However, in a later study, Eyring et al. (2007) used a multi-model approach to compare both the ensemble mean as well as individual model results to observational data and found better agreement than in these previous studies of ship emissions. Nevertheless, little work has been undertaken to quantify the impact of resolution on ship plumes themselves without plume parametrization. In this paper we construct a model specifically to investigate the impact of resolution on the photochemical system and apply it to the emissions from ships. We run the model at various resolutions and then quantify the impact of resolution on the $\mathrm{O}_{3}-\mathrm{HO}_{\mathrm{x}}-\mathrm{NO}_{\mathrm{x}}$ chemistry of a ship plume.

This paper is organized as follows. Section 2 describes the physical system we model and in Sect. 3 we give all of the technical details of our model. We discuss the highest resolution runs of our model in Sect. 4.1 and then report the results of degrading the model's resolution in Sect. 4.2. Conclusions are given in Sect. 5.

\section{Physical and chemical scenario}

Our goal is to model the emissions plume of a typical merchant ship travelling across the open ocean through the remote tropical MBL. We choose a location based on the Barbados Oceanographic and Meteorological Experiment (BOMEX) project (Holland, 1972) and use wind data derived from an offline run of a large eddy model (LEM) case study of BOMEX (Siebesma and Cuijpers, 1995; Brown, 1999). In this south Atlantic trade wind region $\left(15^{\circ} \mathrm{N}, 54^{\circ} \mathrm{W}\right)$, winds are generally light to moderate and there is a shallow layer of non-precipitating cumulus cloud.

Typical translation speeds of merchant and military ships used in previous studies range from $7.7-12.6 \mathrm{~ms}^{-1}$ (Liu et al., 2000) and 5-12 $\mathrm{ms}^{-1}$ (Hobbs et al., 2000). In both of the previous studies ship speeds were measured in field campaigns; Hobbs et al. (2000) used data gathered from ships in the Monterey Area Ship Track (MAST) study. The ground-relative mean wind speed in our simulations is taken to be $1 \mathrm{~ms}^{-1}$ in the negative $\mathrm{x}$-direction and the ship emission source is held stationary relative to the ground. Therefore, if the variations in boundary-layer structure with the ground-relative wind are neglected, the prescribed wind field of $1 \mathrm{~ms}^{-1}$ relative to the ship can be interpreted as representing a ground-relative wind of $4-11.6 \mathrm{~ms}^{-1}$, with the ship moving in the same direction as this steady breeze. Explicitly simulating these stronger ground-relative winds (with a moving ship) would be expected to increase the shear-driven mixing in the turbulent boundary-layer, but since investigating the role of a variety of boundary-layer structures was beyond the scope of this study this effect was neglected. Other ship-relative wind relationships are also of interest (e.g. Song et al., 2003), but due to the difficulty of resolving the plume over a much larger domain, which would require substantially greater computational resources, we choose to concentrate on the aforementioned scenario.

Ship emissions are assumed to take place into initially unpolluted MBL air that is typical of the tropical location of the BOMEX experiment. Because most $\mathrm{NO}_{\mathrm{x}}$ emitted by fossil fuel combustion consists mainly of NO (EPA, 2000; Hewitt, 2001), our model ship releases NO at a point source, directly into the MBL. The initial trace gas concentrations are assumed to be uniform throughout the MBL and are determined by running the photochemistry model for $25 \mathrm{~h}$ with zero emission of NO to establish a diurnal cycle of "clean" MBL chemistry. The clean MBL run was spunup from concentrations for all species set to zero except for $\left[\mathrm{O}_{3}\right]=30 \mathrm{ppb},\left[\mathrm{NO}_{2}\right]=30 \mathrm{ppt},\left[\mathrm{CH}_{2} \mathrm{O}\right],\left[\mathrm{CH}_{3} \mathrm{OOH}\right]$ and $\left[\mathrm{H}_{2} \mathrm{O}_{2}\right]$ (all $100 \mathrm{ppt}$ ). Ship emissions of NO commence at noon local time into the clean MBL background. The variability of $\mathrm{NO}_{\mathrm{x}}$ emission scenarios in the literature (Hobbs et al., 2000; Song et al., 2003; Sinha et al., 2003; von Glasgow et al., 2003; Chen et al., 2005) stems from the differences in vessel and engine type and average ship speed under investigation. The range of emission factors spans 12 to 65 grams of NO per kg of fuel burned. In our simulation, we emit NO into a single grid-box at the lowest vertical level at a rate of $33 \mathrm{~g} \mathrm{~s}^{-1}$. This rate is obtained from the case of a medium speed compression ignition marine engine using 50 tons of fuel per day emitting $\mathrm{NO}_{\mathrm{x}}$ at a rate of $57 \mathrm{~kg}$ per ton of fuel (Corbett and Fischbeck, 1998; Corbett and Koehler, 2003).

\section{Model equations and numerical implementation}

In order to investigate the impact of model resolution on the photochemistry of the MBL we construct a photochemical transport model of the MBL capable of running at a high resolution (compared to a global composition transport model), but also capable of having its numerical grid systematically coarsened to progressively lower resolutions. 
The model equations to be solved are

$\frac{\partial q_{n}}{\partial t}+\boldsymbol{u} \cdot \nabla q_{n}=H_{n}(\boldsymbol{q})+S_{n}, \quad n=1, \ldots, N$,

for the vector of chemical species concentrations $\boldsymbol{q}=\left\{q_{1}, q_{2}, \ldots, q_{N}\right\}$, where the number of species $N=12$. The initial conditions for all species are set to the uniform MBL concentrations described in Sect. 2. The source term $S_{n}$, which is non-zero only for the species NO, is modelled by instantaneously diluting the total NO emitted over a model time-step into the model grid-cell containing the ship stack. The advecting velocity field $\boldsymbol{u}$ is derived from the output of an LEM simulation, as described in Sect. 3.1. Section 3.2 discusses the advection scheme used to advance the left hand side of Eq. (1). Finally, the details of the chemical species $\boldsymbol{q}$ and chemistry scheme $H_{n}(\boldsymbol{q})$ are set out in Sect. 3.3.

The model domain is taken to be periodic in the $y$-direction (cross-flow direction). In the $\mathrm{x}$-direction (along-flow direction), inflow conditions based on clean air MBL concentrations are imposed at the upstream boundary and outflow conditions at the downstream boundary. The dimensions of our high resolution domain are $115.2 \mathrm{~km} \times 9.6 \mathrm{~km} \times 1.92 \mathrm{~km}$. The region of the domain above $1.92 \mathrm{~km}$ (up to $3 \mathrm{~km}$ ) is modelled by a reservoir of (spatially) uniform concentration air. Free exchange and mixing of air occurs between this reservoir and the main high resolution part of the domain below. Note that the reservoir is located above the level of imposed subsidence (approximately $1.5 \mathrm{~km}$ ) in the LEM simulation described in Sect. 3.1.

The mean wind velocity, relative to the ship stack, in our simulations is taken to be $1 \mathrm{~ms}^{-1}$ in the $\mathrm{x}$-direction. The plume remains in the domain for approximately $36 \mathrm{~h}$ before exiting the domain at the downstream boundary. Therefore, Eq. (1) is integrated for this period of time in order to model the chemical evolution of the plume until it reaches a near steady state.

\subsection{The advecting velocity field: LEM simulation}

We use the UK Meteorological Office's Large Eddy Model (LEM) (version 2.3) (Gray et al., 2001) to provide high resolution winds suitable for the modelling of a ship plume. For the present investigation a classic idealised MBL simulation of trade wind cumulus based on the BOMEX case study (Siebesma and Cuijpers, 1995; Brown, 1999) is chosen. Cumulus-topped boundary layers are common over the worlds oceans; therefore, this is a simulation of an extremely common MBL situation (sensitivities to boundary layer meteorology will be addressed in future work). Additionally, the LEM simulation of BOMEX is appropriate because the model simulations have been extensively evaluated during studies performed within the "Global Energy and Water Cycle Experiment Cloud System Study" (GCSS) programme (Brown, 1999). Consequently, the simulations produce a sufficiently realistic boundary layer for the purposes of this study.

Version 2.3 of the Met Office LEM is a non-hydrostatic model that can be run in one, two or three dimensions. The model has periodic lateral boundary conditions, a no-slip base and a free-slip lid. To create the wind field, the model setup of Brown (1999) is used, with a larger horizontal domain $(9.6 \mathrm{~km} \times 9.6 \mathrm{~km}$ rather than $6.4 \mathrm{~km} \times 6.4 \mathrm{~km})$ and with larger horizontal grid-spacings $(200 \mathrm{~m}$ rather than $100 \mathrm{~m})$ in order to reduce computational costs. The model domain is $3 \mathrm{~km}$ high and the vertical grid-spacing is $40 \mathrm{~m}$. A Newtonian damping layer is applied above $2300 \mathrm{~m}$ to prevent the reflection of gravity waves from the top of the model. Because the LEM simulation has periodic lateral boundary conditions, we use the domain to create a longer domain for the chemical and dynamical plume model in this study. This extended domain is described later in this section.

Cloud water is modelled with a single moment scheme, and the LEM rain scheme is not switched on. Surface sensible and latent heat fluxes are prescribed $\left(8.04 \mathrm{~W} \mathrm{~m}^{-2}\right.$ and $130.052 \mathrm{~W} \mathrm{~m}^{-2}$ respectively) so that in the present experiments there is no diurnal cycle in the model winds. Radiative effects are not explicitly modelled, instead a radiative cooling of $2 \mathrm{~K} \mathrm{day}^{-1}$ is imposed from the surface to $1500 \mathrm{~m}$, which then decreases linearly to zero at $2500 \mathrm{~m}$. Note that the diurnal cycle in the MBL is not as pronounced as in a boundary layer over land (Stull, 1988); therefore, the absence of a diurnal cycle in the wind fields is not believed to be a major issue for the current study. A large-scale subsidence is imposed with a maximum subsidence rate of $0.0065 \mathrm{~m} \mathrm{~s}^{-1}$ at $1500 \mathrm{~m}$ (linearly decreasing to zero at the surface and $2100 \mathrm{~m}$ ). A drying of $1.2 \times 10^{-8} \mathrm{~g} \mathrm{~kg}^{-1} \mathrm{~s}^{-1}$ is applied from the surface to $300 \mathrm{~m}$ (decreasing linearly to zero from 300 to $500 \mathrm{~m}$ ) to represent large-scale horizontal advective drying in the subcloud layer. As mentioned above, the LEM domain is periodic in the across-plume direction. There are no mean transverse winds; the asymmetries in the plume appearance in this direction are due to the eddies resolved by the LEM. In addition to the model winds, the LEM simulation also provided temperature and pressure profiles for use in the model chemistry scheme.

Given that the zonal wind speed is approximately $1 \mathrm{~m} \mathrm{~s}^{-1}$ in these simulations, the plume edge will reach the end of the LEM's $9.6 \mathrm{~km}$ domain in about $160 \mathrm{~min}$. This is not enough time to simulate the full impact of $\mathrm{NO}_{\mathrm{x}}$ emissions on the system. A longer model domain in the zonal direction is required in order to simulate the $36 \mathrm{~h}$ needed to examine the impact of the ship plume on MBL photochemistry. To increase our domain size with the minimum off-line computational expense, we "tile" the output of the LEM (not the LEM domain itself) along the zonal direction to form an extended domain for the plume to occupy. The periodic boundary condition used for the initial LEM simulation is ideally suited for this. We use 12 tiles for the chemistry-advection model, and thus we go from a $9.6 \mathrm{~km} \times 9.6 \mathrm{~km} \times 1.92 \mathrm{~km}$ 
LEM simulation to a $115.2 \mathrm{~km} \times 9.6 \mathrm{~km} \times 1.92 \mathrm{~km}$ simulation with the chemistry-advection model.

The LEM generates wind fields for a $6 \mathrm{~h}$ period. The photochemical transport model simulations are run for $36 \mathrm{~h}$ so the LEM meteorological fields are reused for each $6 \mathrm{~h}$ period of the photochemical transport model integration (see Sect. 3.2 for details). As noted above, the diurnal cycle in the MBL wind is not essential to our study and is not modelled; thus, the recycling of LEM winds is reasonable for our purposes.

\subsection{Advection and the degrading of resolution}

A standard upwind advection scheme (see e.g. LeVeque, 2002) is used to solve the advection equation for the mean mixing ratio of the active chemical species $q_{n}(n=1, \ldots, 12)$, with $\boldsymbol{u}$ derived from the LEM output. Note that the supplied wind-field is non-divergent $\nabla \cdot \boldsymbol{u}=0$. As mentioned above, all simulations are run for $36 \mathrm{~h}$ which ensures that transient model behaviour can be eliminated. The LEM winds are supplied at $1 \mathrm{~min}$ intervals; we interpolate in time to match our advection time step of $3 \mathrm{~s}$ which is chosen to satisfy the Courant-Friedrichs-Lewy (CFL) condition. We performed numerical tests which established that model solutions are not very sensitive to the degradation in the temporal resolution of the wind fields due to the interpolation in time. After the $6 \mathrm{~h}$ of LEM winds have been used, the wind fields are interpolated back to those at $t=0$ and the time series for $\boldsymbol{u}$ is used again.

A natural first approach to degrade the resolution of the wind fields, for use with a lower resolution version of the advection model, is simply to average the wind component normal to each grid-box boundary. Because the LEM supplies a divergence-free wind field, the averaging process maintains the divergence-free property of the wind field while rendering it suitable for advection with a coarser grid (i.e. larger grid boxes). Hence, we can calculate a single flux along each edge of the larger grid box. A second alternative to degrade the resolution is to sum the positive and negative wind components normal to each grid-box boundary separately. This approach allows a two-way exchange at each grid box boundary. In Appendix A, we demonstrate with a passive tracer that this second method is considerably more accurate than the first because by using the two-way exchange, we retain the transports due to the unresolved scales of the LEM winds, much as in a sub-grid turbulence closure scheme. If the first (naive) option is used, it is found that the plume spreads too rapidly in the horizontal directions and remains trapped relatively near the surface compared to the higher resolution simulations. The two-way flux scheme therefore allows an important effect of the sub-grid winds to be captured in the lower resolution simulations. In coarse resolution CTMs, a boundary layer turbulence scheme is usually employed to model the same sub-grid wind effects.
The highest resolution gridbox in this study is $200 \mathrm{~m} \times 200 \mathrm{~m}$ in the horizontal and $40 \mathrm{~m}$ in the vertical, which is based on the resolution of the LEM output, and we refer to it as the $\mathrm{C} 1$ case. When we coarsen the high resolution domain, we reduce the resolution in all three directions, horizontal and vertical, while maintaining the divergence-free LEM wind field. The result of this coarsening is to increase grid box volumes by $n^{3}$ where $n=2,4,8,16,48$ and we refer to these cases as $\mathrm{C} n$ in the figures. To ensure that we maintain a consistent physical form of the plume across model resolutions, the two-way flux exchange method described above and in Appendix A is used. This method preserves the sub-gridscale winds as we coarsen the chemistry model resolution.

\subsection{Chemistry scheme}

Our chemistry scheme includes the key interactions of $\mathrm{NO}_{\mathrm{x}}-$ $\mathrm{HO}_{\mathrm{x}}-\mathrm{O}_{3}$ and the relevant photochemistry in the MBL. We designed the chemical model to focus on the key reactions of $\mathrm{NO}_{\mathrm{x}}$, in the ship plume and surrounding air, with $\mathrm{O}_{3}$ and the hydroxyl radical $\mathrm{OH}$. To this end, we follow the evolution of twelve critical species while maintaining other species constant. We hold three species constant over the entire model run: $\mathrm{H}_{2} \mathrm{O}, \mathrm{CH}_{4}$ and $\mathrm{CO}$. These are long-lived species with respect to the model integration time.

Table 1 summarizes the chemical reactions we use to model the tropospheric chemistry in the MBL. The reaction rates are taken from the Master Chemical Mechanism (http://mcm.leeds.ac.uk/MCM/). We model the evolution of twelve chemical species: $\mathrm{O}_{3}, \mathrm{NO}, \mathrm{NO}_{2}, \mathrm{NO}_{3}, \mathrm{OH}, \mathrm{HO}_{2}$, $\mathrm{CH}_{3} \mathrm{O}_{2}, \mathrm{CH}_{2} \mathrm{O}, \mathrm{CH}_{3} \mathrm{OOH}, \mathrm{H}_{2} \mathrm{O}_{2}, \mathrm{HNO}_{3}$ and $\mathrm{N}_{2} \mathrm{O}_{5}$. We ignore $\mathrm{HNO}_{2}$ and $\mathrm{HNO}_{4}$ chemistry as these species do not play a significant role in the MBL. VOC chemistry is not included in the model. The primary reason is numerical efficiency, as the addition of VOC chemistry adds a significant computational burden to the model. A second reason is to simplify the experimental design, allowing the present experiments to focus solely on $\mathrm{NO}_{\mathrm{x}}$ photochemistry, rather than attempting to map the more uncertain $\mathrm{NO}_{\mathrm{x}}-\mathrm{VOC}$ parameter space. Thirdly, in the conditions explored here the background VOC levels are low due to the remote nature of the atmosphere being simulated. At the low concentrations typical of the remote ocean, the impact of VOCs on $\mathrm{OH}$ and $\mathrm{O}_{3}$ production is small (Sommariva et al., 2006).

The model run begins on Julian day 80 , the spring equinox. The solar zenith angle is calculated as a function of date, time of day, latitude and longitude. Vertical profiles of temperature and pressure taken from the LEM model run offline are used to calculate reaction rates for each vertical model level. We use a GEAR (VODE) solver (Brown et al., 1989) to integrate the chemistry component of the system of differential equations (1). We allow the model to spin up for $12 \mathrm{~h}$ and use only the last $24 \mathrm{~h}$ of the simulation in our study. 
Table 1. Chemical reactions modelled. Derived from the Master Chemical Mechanism where $\zeta$ is solar zenith angle; $T$ temperature $[\mathrm{K}]$; $p$ pressure [hPa]; and $m$ number density of air [molecules $\mathrm{cm}^{-3}$ ]. $k_{12}$ reaction product is $\mathrm{H}_{2} \mathrm{O} ; k_{18}$ represents PAN decomposition; $k_{19}$ represents the heterogeneous uptake of $\mathrm{N}_{2} \mathrm{O}_{5}$.

\begin{tabular}{|c|c|}
\hline $\mathrm{O}_{3}+h v \rightarrow \mathrm{O}^{1} \mathrm{D}$ & $J_{1}=6.073 \times 10^{-5} \cos \left(\zeta^{1.743}\right) \exp (-0.474 / \cos \zeta)$ \\
\hline $\mathrm{NO}_{2}+h v \rightarrow \mathrm{NO}+\mathrm{O}_{3}$ & $J_{2}=1.165 \times 10^{-2} \cos \left(\zeta^{0.244}\right) \exp (-0.267 / \cos \zeta)$ \\
\hline $\mathrm{CH}_{2} \mathrm{O}+h v \rightarrow \mathrm{CO}$ & $J_{3}=6.853 \times 10^{-5} \cos \left(\zeta^{0.477}\right) \exp (-0.353 / \cos \zeta)$ \\
\hline $\mathrm{CH}_{2} \mathrm{O}+h v \rightarrow \mathrm{CO}+2 \mathrm{HO}_{2}$ & $J_{4}=4.642 \times 10^{-5} \cos \left(\zeta^{0.762}\right) \exp (-0.353 / \cos \zeta)$ \\
\hline $\mathrm{NO}_{3}+h v \rightarrow \mathrm{NO}$ & $J_{5}=2.485 \times 10^{-2} \cos \left(\zeta^{0.168}\right) \exp (-0.108 / \cos \zeta)$ \\
\hline $\mathrm{NO}_{3}+h v \rightarrow \mathrm{NO}_{2}+\mathrm{O}_{3}$ & $J_{6}=1.747 \times 10^{-1} \cos \left(\zeta^{0.155}\right) \exp (-0.125 / \cos \zeta)$ \\
\hline $\mathrm{NO}+\mathrm{O}_{3} \rightarrow \mathrm{NO}_{2}$ & $k_{3}=1.4 \times 10^{-12} \exp (-1310 / T)$ \\
\hline $\mathrm{OH}+\mathrm{CO} \rightarrow \mathrm{HO}_{2}$ & $k_{4}=1.30 \times 10^{-13}$ \\
\hline $\mathrm{OH}+\mathrm{CH}_{4} \rightarrow \mathrm{CH}_{3} \mathrm{O}_{2}$ & $k_{5}=9.65 \times 10^{-20}\left(T^{2.58}\right) \exp (-1082 / T)$ \\
\hline $\mathrm{HO}_{2}+\mathrm{NO} \rightarrow \mathrm{OH}+\mathrm{NO}_{2}$ & $k_{6}=3.6 \times 10^{-12} \exp (270 / T)$ \\
\hline $\mathrm{HO}_{2}+\mathrm{O}_{3} \rightarrow \mathrm{OH}$ & $k_{7}=2.03 \times 10^{-16}(T / 300)^{4.57} \exp (693 / T)$ \\
\hline $\mathrm{CH}_{3} \mathrm{O}_{2}+\mathrm{NO} \rightarrow \mathrm{NO}_{2}+\mathrm{CH}_{2} \mathrm{O}+\mathrm{HO}_{2}$ & $k_{8}=1.82 \times 10^{-13} \exp (416 / T)$ \\
\hline $\mathrm{CH}_{3} \mathrm{O}_{2}+\mathrm{HO}_{2} \rightarrow \mathrm{CH}_{3} \mathrm{OOH}+\mathrm{O}_{2}$ & $k_{9}=3.80 \times 10^{-13} \exp (780 / T)$ \\
\hline $\mathrm{HO}_{2}+\mathrm{HO}_{2} \rightarrow \mathrm{H}_{2} \mathrm{O}_{2}$ & $k_{10}=2.20 \times 10^{-13} \exp (600 / T)+m 1.90 \times 10^{-33} \exp (980 / T)$ \\
\hline $\mathrm{OH}+\mathrm{NO}_{2} \rightarrow \mathrm{HNO}_{3}$ & $\begin{aligned} k_{11} & =k_{0} k_{i} f /\left(k_{0}+k_{i}\right) \quad\left[k_{0}=m 3.3 \times 10^{-30}(T / 300)^{-3}\right. \\
k_{i} & \left.=4.1 \times 10^{-11}, \quad f=10^{\left\{\log _{10} 0.4 /\left(1+\left(\log _{10}\left(k_{0} / k_{i}\right)\right)^{2}\right)\right\}}\right]\end{aligned}$ \\
\hline $\mathrm{OH}+\mathrm{HO}_{2} \rightarrow$ & $k_{12}=4.80 \times 10^{-11} \exp (250 / T)$ \\
\hline $\mathrm{CH}_{3} \mathrm{O}_{2}+\mathrm{CH}_{3} \mathrm{O}_{2} \rightarrow$ & $k_{13}=1.82 \times 10^{-13} \exp (416 / T)$ \\
\hline $\mathrm{NO}_{2}+\mathrm{O}_{3} \rightarrow \mathrm{NO}_{3}$ & $k_{14}=1.40 \times 10^{-13} \exp (-2470 / T)$ \\
\hline $\mathrm{NO}+\mathrm{NO}_{3} \rightarrow 2 \mathrm{NO}_{2}$ & $k_{15}=1.80 \times 10^{-11} \exp (110 / T)$ \\
\hline $\mathrm{NO}_{2}+\mathrm{NO}_{3} \rightarrow \mathrm{N}_{2} \mathrm{O}_{5}$ & $\begin{aligned} k_{16}= & k_{0} k_{i} f /\left(k_{0}+k_{i}\right), \quad\left[k_{i}=1.90 \times 10^{-12}(T / 300)^{0.2}\right. \\
& k_{0}=m 3.60 \times 10^{-30}(T / 300)^{-4.1} \\
& \left.f=10^{\left\{\log _{10} 0.35 /\left(1+\left(\log _{10}\left(k_{0} / k_{i}\right)\right)^{2}\right)\right\}}\right]\end{aligned}$ \\
\hline $\mathrm{N}_{2} \mathrm{O}_{5} \rightarrow \mathrm{NO}_{2}+\mathrm{NO}_{3}$ & 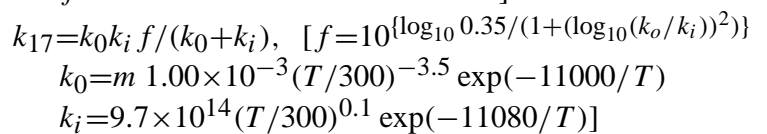 \\
\hline$\rightarrow \mathrm{NO}_{2}$ & $k_{18}=9.25 \times 10^{3}$ \\
\hline $\mathrm{N}_{2} \mathrm{O}_{5} \rightarrow 2 \mathrm{HNO}_{3}$ & $k_{19}=4.0 \times 10^{-4}$ \\
\hline $\mathrm{NO}_{2}+\mathrm{NO}_{3} \rightarrow \mathrm{NO}_{2}+\mathrm{NO}$ & $k_{20}=4.50 \times 10^{-14} \exp (-1260 / T)$ \\
\hline
\end{tabular}

\section{Results}

\subsection{High resolution simulations}

Results are shown for times on the second day of the run and all times are given as local time. Figures 1 and 2 show results for the highest resolution (C1) simulation.

Figure 1 shows the horizontal extent of the $\mathrm{NO}_{\mathrm{x}}$ plume at the lowest model level. Highest $\mathrm{NO}_{\mathrm{x}}$ concentrations are near the source of NO emission which is the lowest level box located at the eastward edge and at the channel centre in the y-direction $(x=115.2 \mathrm{~km}, y=4.8 \mathrm{~km})$. The $\mathrm{NO}_{\mathrm{x}}$ plume is mainly being advected westward relative to the ship stack, and spreads out due to turbulent diffusion downwind of the source. Figure 2 shows a vertical cross-section of the $\mathrm{NO}_{\mathrm{x}}$ plume at four locations downstream from the source. Defining the plume boundary is subjective, but the $\left[\mathrm{NO}_{\mathrm{x}}\right]=316 \mathrm{ppt}$ isosurface can be taken as a reasonable definition, and is also contoured in Fig. 1. Then the plume height and across-plume width generally increase with distance downstream from the source. The height does not appear to increase from 8 to 20 $\mathrm{km}$ downstream and we note that much of the plume remains generally trapped in the vertical below the level of imposed subsidence in the LEM model (approximately $1.5 \mathrm{~km}$ ).

\subsection{Results: impact of resolution}

In this section we show how the spatial patterns of $\mathrm{NO}_{\mathrm{x}}, \mathrm{O}_{3}$ and $\mathrm{OH}$ concentrations vary as model resolution is changed. In particular, we describe the $\mathrm{OH}$ "halo" pattern. We also assess the impact of changing the model resolution by computing the spatial mean over the model domain of several relevant quantities: $\mathrm{OH}$ concentrations, $\mathrm{NO}_{\mathrm{x}}$ lifetime and $\mathrm{O}_{3}$ production efficiency. These mean values are calculated at noon (local time) on day 2 of the model integration. Finally, we compare the full ship emission runs to clean runs, those without ship emissions.

Figure 3 shows snapshots of the lowest vertical level of the ship plume in $\mathrm{NO}_{\mathrm{x}}, \mathrm{O}_{3}$ and $\mathrm{OH}$ at noon on 


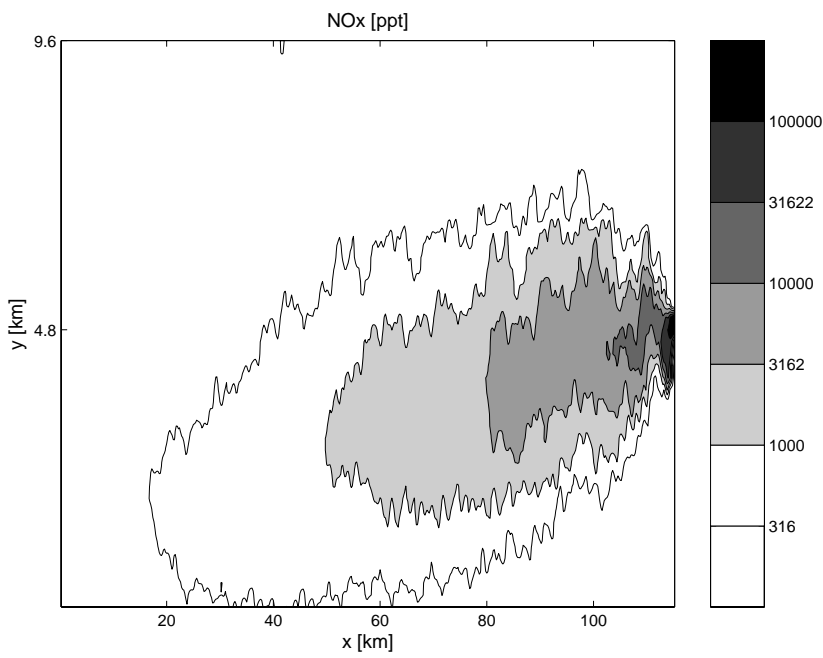

Fig. 1. Lowest vertical level of the $\mathrm{NO}_{\mathrm{x}}\left(\mathrm{NO}+\mathrm{NO}_{2}\right)$ plume in the highest resolution $(\mathrm{C} 1)$ experiment at noon (local time) on day 2, after the plume has evolved for $24 \mathrm{~h}$. Darker shading indicates higher $\mathrm{NO}_{\mathrm{x}}$ concentrations. Contour intervals are base 10 logarithmic in units of ppt.

day 2 for five different resolutions of grid box volume: $200 \mathrm{~m} \times 200 \mathrm{~m} \times 40 \mathrm{~m}(\mathrm{C} 1), 400 \mathrm{~m} \times 400 \mathrm{~m} \times 80 \mathrm{~m}(\mathrm{C} 2)$, $800 \mathrm{~m} \times 800 \mathrm{~m} \times 160 \mathrm{~m}(\mathrm{C} 4), 1600 \mathrm{~m} \times 1600 \mathrm{~m} \times 320 \mathrm{~m}(\mathrm{C} 8)$ and $3200 \mathrm{~m} \times 3200 \mathrm{~m} \times 640 \mathrm{~m}(\mathrm{C} 16)$. The plume becomes more diffuse as we coarsen the grid boxes (moving down the page). At all model resolutions we can clearly distinguish the heart of the ship plume as shown in Fig. 3a (left column) by very high $\mathrm{NO}_{\mathrm{x}}$ coincident with the $\mathrm{O}_{3}$ and $\mathrm{OH}$ minima in Fig. $3 b$ (middle column) and 3c (right column). It is to be expected that when $\mathrm{NO}_{\mathrm{x}}$ is at very high levels it will consume $\mathrm{O}_{3}$ and $\mathrm{OH}$ rapidly. At all resolutions, the area within the $\mathrm{NO}_{\mathrm{x}}$ plume contour line $3162 \mathrm{ppt}$ overlaps with lower $\mathrm{O}_{3}(<24 \mathrm{ppb})$ and lower $\mathrm{OH}$ concentrations $\left(<4 \times 10^{6}\right.$ molecules $\left.\mathrm{cm}^{-3}\right)$. For all resolutions, the $\mathrm{OH}$ levels are highest in a "halo" which lies on top of the $\mathrm{NO}_{\mathrm{x}}$ plume edge where the $\mathrm{NO}_{\mathrm{x}}$ values are roughly between 300 and 1000 ppt. This halo is consistent with our knowledge of the $\mathrm{OH}$ response to $\mathrm{NO}_{\mathrm{x}}$ in tropospheric photochemistry. In their observational work, Sinha et al. (2003) discuss the effect that $\mathrm{NO}_{\mathrm{x}}$ and $\mathrm{O}_{3}$ downwind of ship plumes have on $\mathrm{OH}$, that is, to elevate $\mathrm{OH}$ levels, and this enhancement is captured in our simulations at all resolutions.

Figure 4 gives further evidence of this "halo" of enhanced $\mathrm{OH}$ in this across-plume 1-D section of $\mathrm{OH}$ concentrations at different resolutions. At the edge of the plume, in the region where the plume air is mixing with the cleaner background air, $\mathrm{OH}$ levels are enhanced. This is due to the presence of moderate amounts of $\mathrm{NO}_{\mathrm{x}}$ at the plume edge and high levels of $\mathrm{O}_{3}$ which have not yet been consumed by the $\mathrm{NO}_{\mathrm{x}}$ plume. Chen et al. (2005) calculate an average $\mathrm{OH}$ value using observed $\mathrm{NO}_{\mathrm{x}}$ in ship plumes in conjunction with a pho- tochemical box model and determine that $\mathrm{OH}$ in the plume is between 1.2 and 2.7 times higher than in the ambient air. In Fig. 4, we see that $\mathrm{OH}$ concentrations at the plume edge are about 1.4 times higher than in the ambient air and can be up to 12 times higher in the heart of the plume. Depending on where one draws the edge of the plume, mean in-plume $\mathrm{OH}$ concentrations can vary a great deal.

Next, we compute a spatial average over the entire 3-D domain $(115.2 \mathrm{~km} \times 9.6 \mathrm{~km} \times 1.92 \mathrm{~km})$ of $\mathrm{NO}_{\mathrm{x}}, \mathrm{OH}, \mathrm{NO}_{\mathrm{x}}$ lifetime and Ozone Production Efficiency (OPE). We define the $\mathrm{NO}_{\mathrm{x}}$ lifetime as ratio of concentration of $\mathrm{NO}_{\mathrm{x}}$ to rate of loss of $\mathrm{NO}_{\mathrm{x}}$, where, in our model, the $\mathrm{NO}_{\mathrm{x}}$ loss rate is exactly equivalent to the production rate of nitric acid $\left(\mathrm{HNO}_{3}\right)$. OPE is defined as the number of $\mathrm{O}_{3}$ molecules produced given the number of $\mathrm{NO}_{\mathrm{x}}$ molecules consumed in a unit volume and is calculated in the model as the mean ratio of $\mathrm{O}_{\mathrm{x}}$ production rate to mean $\mathrm{NO}_{\mathrm{x}}$ loss rate (Lin et al., 1988). All four quantities appear to be linearly dependent on resolution (i.e. on the logarithm of the gridbox volume) for cases $\mathrm{C} 4, \mathrm{C} 8$, $\mathrm{C} 16$ and $\mathrm{C} 48$ (see Figs. 5, 6 and 7, $\mathrm{NO}_{\mathrm{x}}$ not shown). Domain mean $\mathrm{NO}_{\mathrm{x}}$ decreases steadily from the highest resolution case 412 ppt to 231 ppt at C48, a decrease of $44 \%$. The two highest resolution cases $\mathrm{C} 1$ and $\mathrm{C} 2$ appear to asymptote to a similar value in all three figures. In Sect. 3.2, we explained that our coarsening method uses a two-way exchange at the grid box interfaces; we speculate that perhaps for these two highest resolution cases the two-way exchange creates similar enough conditions, for the meteorology used here, that $\mathrm{C} 2$ becomes a sufficiently high resolution to achieve the limiting values for our model. Thus, we fit lines to each of the three sets of values, excluding the two highest resolution cases, using a Matlab routine (robustfit.m) which implements robust regression using iteratively re-weighted leastsquares (Holland and Welsch, 1977). Using the parameters from the robust linear fit, we then extrapolate our model results to coarser resolutions, comparable to CTM grid boxes of $1^{\circ} \times 1^{\circ}, 4^{\circ} \times 4^{\circ}$ and $5^{\circ} \times 5^{\circ}$ (we assume that the CTM grid box height is equivalent to our model height, $1.92 \mathrm{~km})$. We consider these extrapolated values in order to put our work into the context of CTM grid scales and of previous ship emission studies using box models.

In a study by von Glasgow et al. (2003), using a box model which is modified via a "simple upscaling approach" to compare with global chemistry models and where ship emissions were taken to be a constant source at the sea surface, they found that $\mathrm{OH}$ can be overestimated by a factor of 2 . When the ship plume is explicitly simulated in our model and then the model resolution is coarsened, we find that the mean amount of $\mathrm{OH}$ in the domain increases, but by less than a factor of 2. In Fig. 5, we show the mean number of $\mathrm{OH}$ molecules for our model run with different grid box volumes and then we extrapolate the results to resolutions compatible with a typical global CTM. The trend is that $\mathrm{OH}$ increases by a few percent each time the gridbox area is increased. The slope of the line is about 0.2 which means that for every 


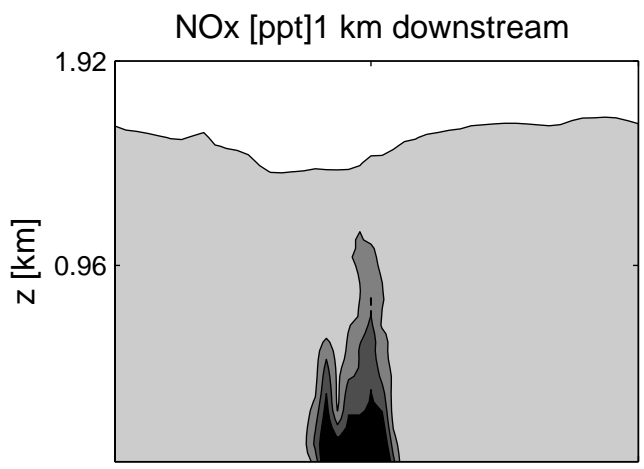

\section{$4 \mathrm{~km}$ downstream}
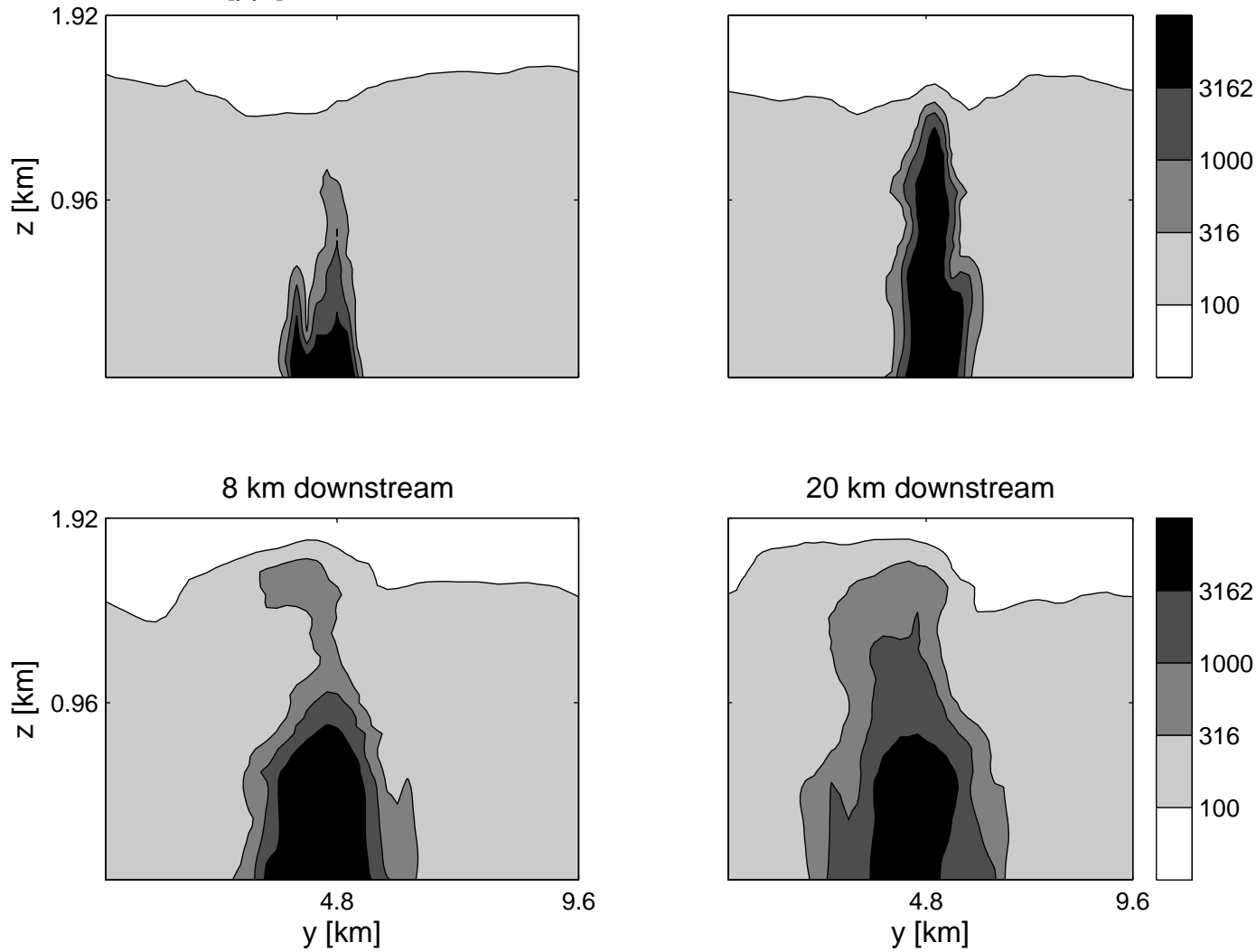

$20 \mathrm{~km}$ downstream

$8 \mathrm{~km}$ downstream

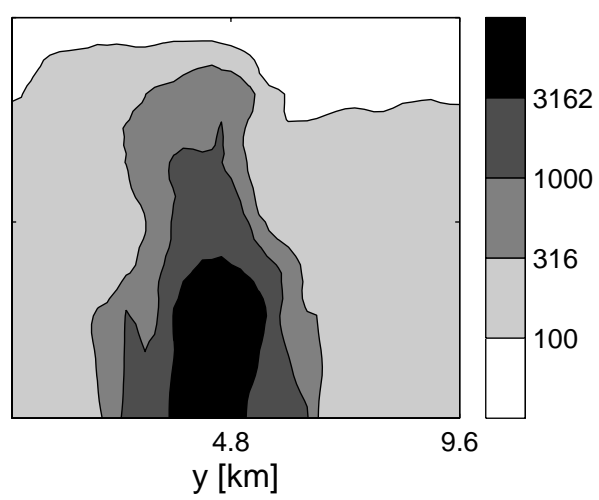

Fig. 2. Vertical sections of $\mathrm{NO}_{\mathrm{x}}$ across the plume at noon (local time) on day 2 for the highest resolution (C1) experiment at $1,4,8$ and $20 \mathrm{~km}$ downstream from the source. Contour intervals are base 10 logarithmic in units of ppt.

factor of 10 by which we increase the grid box volume, we can expect an increase of $2 \times 10^{5}$ molecules of $\mathrm{OH} \mathrm{cm} \mathrm{cm}^{-3}$.

To calculate $\mathrm{NO}_{\mathrm{x}}$ lifetime, first, we compute the domain mean quantities, mass-weighted in the vertical, of $\mathrm{NO}_{\mathrm{x}}$ concentration and $\mathrm{HNO}_{3}$ production rate and then compute the ratio. In our results, the spatial variability of $\mathrm{NO}_{\mathrm{x}}$ lifetime is extremely high across the domain when a ship plume is present. But if we look at the domain mean, $\mathrm{NO}_{\mathrm{x}}$ lifetime decreases steadily with coarsening model resolution. Figure 6 shows that by decreasing spatial resolution we decrease the mean lifetime of $\mathrm{NO}_{\mathrm{x}}$, but only by fractions of an hour each time the resolution is halved. In fact, according to our linear fit, if we increase the grid box volume by a factor of 10 , we can expect a decrease of $0.34 \mathrm{~h}$ or $20 \mathrm{~min}$. The negative trend in $\mathrm{NO}_{\mathrm{x}}$ lifetime is anti-correlated with $\mathrm{OH}$ levels and could indicate that the reaction of $\mathrm{OH}$ with $\mathrm{NO}_{2}$ to produce $\mathrm{HNO}_{3}$ is the main process by which $\mathrm{NO}_{\mathrm{x}}$ is lost. Using a box model forced by data obtained from observations of eight transects of ship plumes in the ITCT ship experiments, Chen et al. (2005) found a strong anti-correlation between $\mathrm{NO}_{\mathrm{x}}$ lifetime and $\mathrm{OH}$ levels from which they conclude that the $\mathrm{OH}+\mathrm{NO}_{2}$ reaction is the primary process by which NOx is lost. In our study we consider PAN decomposition, but not the forma- tion of PAN, which could be another $\mathrm{NO}_{\mathrm{x}}$ sink. In fact, in our model, the $\mathrm{NO}_{\mathrm{x}}$ loss rate is defined as the production rate of $\mathrm{HNO}_{3}$.

Song et al. (2003) speculated that $\mathrm{NO}_{\mathrm{x}}$ lifetime would be 2.5-10 times shorter in the ship plume than in the MBL environment. Chen et al. (2005) measured $\mathrm{NO}_{\mathrm{x}}$ in two ship plumes $100 \mathrm{~km}$ off the California coast, which they state may have been diluting rapidly due to the ship's heading and meteorological conditions and therefore, may have had belowaverage plume concentrations. Then, using a model of exponential decay with plume age and the observations as input Chen et al. (2005) calculated in-plume $\mathrm{NO}_{\mathrm{x}}$ lifetime to be approximately $113 \pm 23 \mathrm{~min}$. In their study, at noon in the "moderately polluted" background air, $\mathrm{NO}_{\mathrm{x}}$ lifetime was about $6.5 \mathrm{~h}$, about $4.7 \mathrm{~h}$ longer than in the ship plume. We calculated the mean $\mathrm{NO}_{\mathrm{x}}$ lifetime in the entire domain (not shown) for a model run with a ship plume and without at different resolutions (C2-C48). There were no notable differences in the zero emission runs between different resolutions. We found that the presence of a ship emitting NO decreases the mean $\mathrm{NO}_{\mathrm{x}}$ lifetime in the domain by approximately $2 \mathrm{~h}$, less than half the difference found in their study. The difference may be due to the fact that in our model the plume 
(a) NOx [ppt]
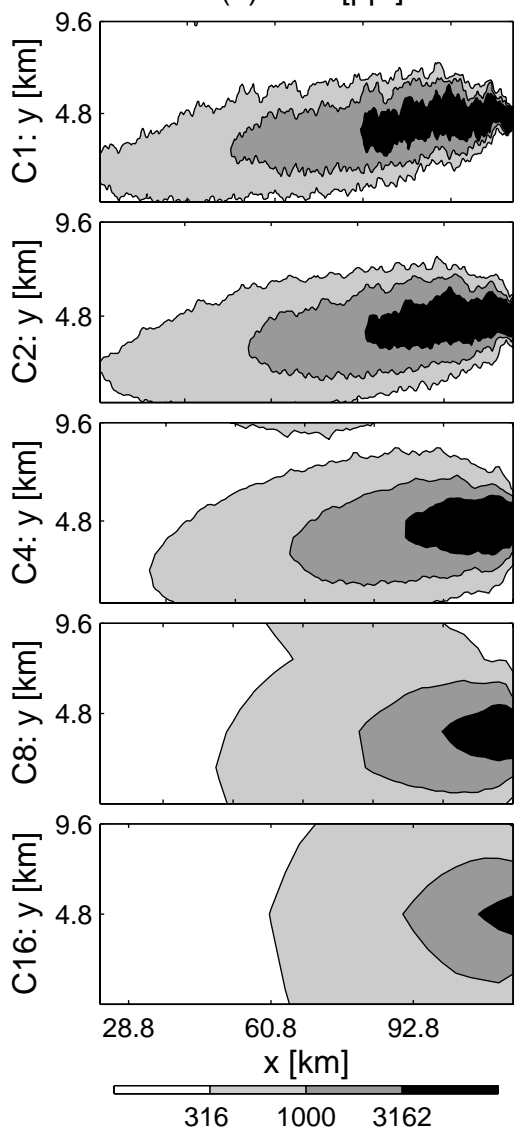

(b) $\bigcirc 3$ [ppb]
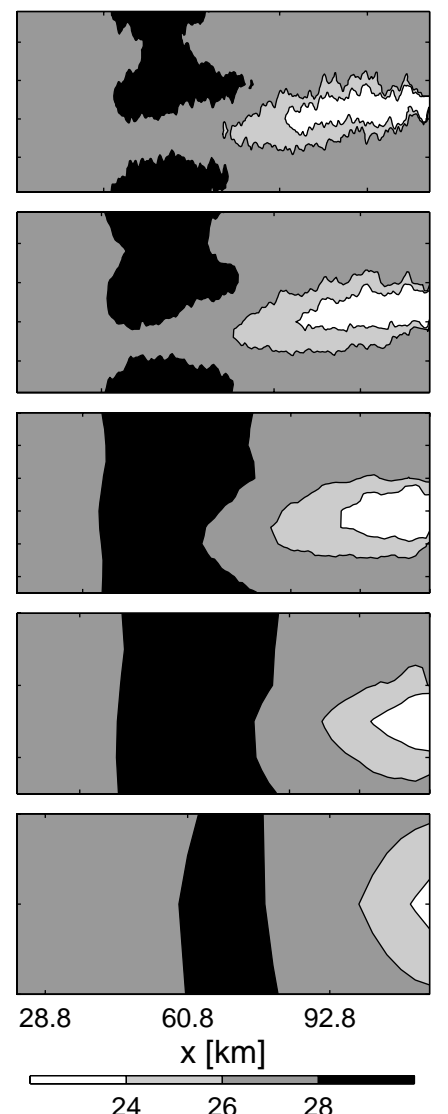

(c) $\mathrm{OH}\left[1 \oint^{6}\right.$ molecules $\left.\mathrm{cm}^{-3}\right]$
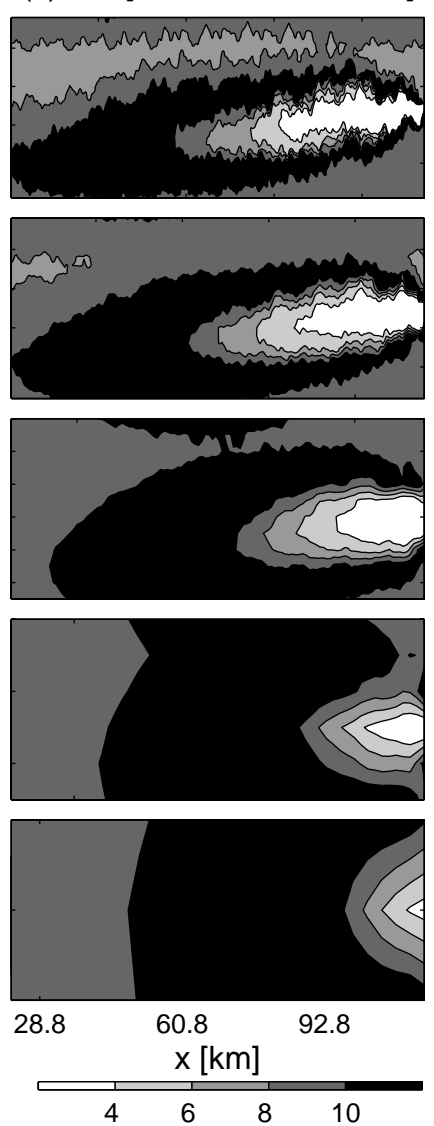

Fig. 3. Lowest vertical level of plume in $\mathrm{NO}_{\mathrm{x}}(\mathbf{a}), \mathrm{O}_{3}(\mathbf{b})$ and $\mathrm{OH}(\mathbf{c})$ at noon (local time) on day 2 for five different model resolutions. First row shows the highest resolution $\mathrm{C} 1$, then below $\mathrm{C} 2, \mathrm{C} 4, \mathrm{C} 8$ and $\mathrm{C} 16$.

is not experiencing rapid dilution in contrast to the observed ship plumes used as input to their model which were possibly very dilute.

Davis et al. (2001) suggested that global CTMs overestimate $\mathrm{NO}_{\mathrm{x}}$ because high concentrations of $\mathrm{OH}$ in-plume reduce $\mathrm{NO}_{\mathrm{x}}$ lifetime in-plume. We find that $\mathrm{OH}$ concentrations are highest (Figs. 3c and 4) and induce the shorter lifetime of $\mathrm{NO}_{\mathrm{x}}$ not in the plume core but on the edge of the plume in the aforementioned $\mathrm{OH}$ "halo" region. The magnitude of the change in $\mathrm{NO}_{\mathrm{x}}$ lifetime may be influenced by VOCs, but the general feature should be robust. Such spatial detail is impossible to represent if ship plumes are not resolved in a model.

Figure 7 shows the OPE at noon on day 2 averaged over all grid boxes in all resolution cases. OPE increases sharply as the grid is coarsened; the slope is about 0.58 which translates to an increase in OPE of 0.58 if the grid box volume increases by a factor of 10 . OPE of the run on the coarsest grid (C48) is $31 \%$ more than the $\mathrm{C} 1$ case. If we extrapolate for larger grid box volumes as we did for mean $\mathrm{OH}$ and $\mathrm{NO}_{\mathrm{x}}$ lifetime, we can see that a $5^{\circ} \times 5^{\circ}$ grid box model would have a mean OPE larger than 10, a clear overestimate of the high resolution ship plume simulation of about $59 \%$. The domain mean $\mathrm{O}_{3}$ concentrations do not obey a linear relationship with changing resolution at noon on day 2; they do not change appreciably from about $26.9 \mathrm{ppb}$ as the resolution is coarsened. However, the maximum $\mathrm{O}_{3}$ is found at the coarsest resolution (27.3 ppb).

As we degrade model resolution we find that the same ship emission rate affects the photochemistry of the MBL in significant ways. In the ship emission runs, when the model resolution decreases from $\mathrm{C} 1$ to $\mathrm{C} 48$ : $\mathrm{OH}$ increases by $8 \%, \mathrm{NO}_{\mathrm{x}}$ lifetime decreases by about $32 \%$ and OPE increases by $31 \%$. If we forecast using the linear fit, consider that the highest resolution case has $15 \%$ less $\mathrm{OH}$ than the $5^{\circ} \times 5^{\circ}$ case, $55 \%$ longer $\mathrm{NO}_{\mathrm{x}}$ lifetime and $59 \%$ less OPE.

When we run the model with a completely clean environment (i.e. no ship emissions) for $36 \mathrm{~h}$, the domain mean values on day 2 at noon for $\mathrm{OH}$, NOx lifetime and OPE are $5.8 \times 10^{6}$ molecules $\mathrm{cm}^{-3}, 6.4 \mathrm{~h}$, and 21.3 , respectively. Comparing the model clean run, without ship emissions to that with ship emissions, $\mathrm{OH}$ increases 59\%-72\% (C1-C48) 


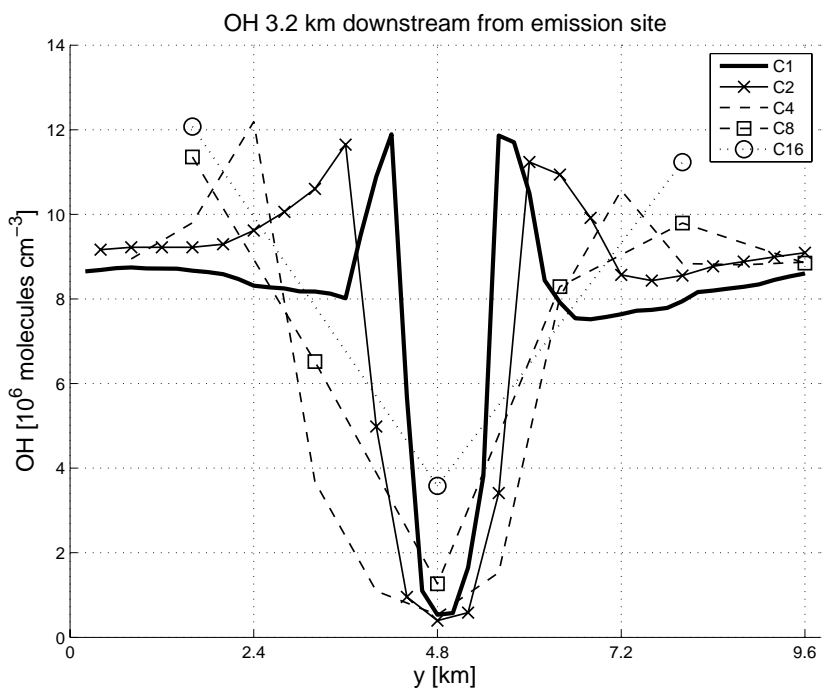

Fig. 4. OH concentrations across the plume on the lowest vertical level $3.2 \mathrm{~km}$ downstream of the emission source for four different resolution runs at noon (local time) on day 2 .

in the presence of ship emissions, $\mathrm{NO}_{\mathrm{x}}$ lifetime decreases $21 \%-46 \%(\mathrm{C} 1-\mathrm{C} 48)$ and OPE decreases $61 \%-70 \%$ (C1C48).

\section{Conclusions}

We have built a high spatial resolution model of the chemistry of the MBL with the inclusion of a point source of NO representing emissions from a ship. A range of identical simulations are run in which we vary the spatial resolution to investigate the effect of resolution on the $\mathrm{OH}$ concentration, lifetime of $\mathrm{NO}_{\mathrm{x}}$ and OPE.

We find that the impacts of the ship NO emissions on the MBL chemistry are highly dependent on the model resolution. This model-resolution dependence may be somewhat sensitive to the tropical meteorological conditions adopted here; consequently, an obvious extension of this work is to determine the robustness of our results over a wide range of different MBL locations and conditions. Within the range of resolutions investigated here and the meteorological conditions adopted, $\mathrm{OH}$ concentrations increase by about $8 \%$ between the highest and lowest resolution simulations. Interpolating this to a resolution typical of CTMs implies approximately a $15 \%$ overestimation of the impact of ship $\mathrm{NO}_{\mathrm{x}}$ on MBL OH concentrations calculated by these models. $\mathrm{NO}_{\mathrm{x}}$ lifetime is anti-correlated with $\mathrm{OH}$ levels which is in agreement with the results of Chen et al. (2005) and could be seen as evidence that the reaction of $\mathrm{OH}$ with $\mathrm{NO}_{2}$ is the key to loss of $\mathrm{NO}_{\mathrm{x}}$, although our model does not include the loss of $\mathrm{NO}_{\mathrm{x}}$ due to the formation of PAN. The ozone production efficiency increases by $31 \%$ between the highest and lowest resolution simulated here. Interpolating to the scales typical

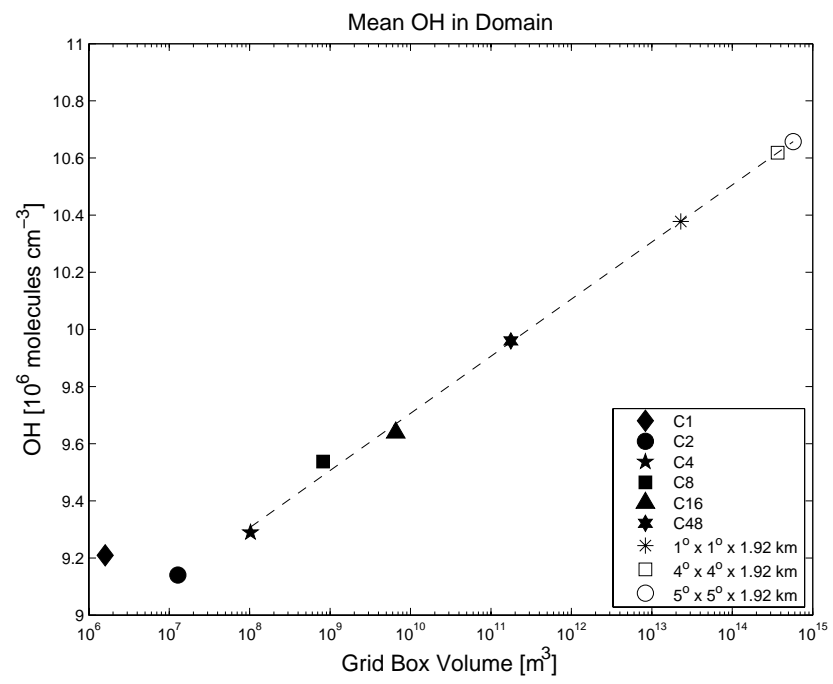

Fig. 5. Domain mean $\mathrm{OH}$ at noon (local time) on day 2 for different resolutions. Dashed line represents best fit to the model results C4, C8, C16 and C48. Solid markers represent our model results and hollow ones are the result of linear extrapolation of our results to larger grid box volume sizes. These larger grid box volumes represent typical CTM resolution with a boundary layer height assumed to be that of our model $(1.92 \mathrm{~km})$. For comparison, a "no emissions" model run produces a domain mean $\mathrm{OH}$ of $5.8 \times 10^{6}$ molecules $\mathrm{cm}^{-3}$ at the same time.

of CTMs we suggest an overestimation of the ozone production by ship emissions within CTMs of approximately $59 \%$. We conclude that spatial resolution has a significant impact on the simulation of the chemistry of ship emissions in the MBL.

An interesting issue is the apparent convergence in our simulations of $\mathrm{OH}$ concentration, $\mathrm{NO}_{\mathrm{x}}$ lifetime and $\mathrm{OPE}$, indicated by the levelling off of the curves in Figs. 5, 6 and 7 for the $\mathrm{C} 1$ (highest resolution) and $\mathrm{C} 2$ simulations. It is unclear at present whether this apparent convergence indicates that we are accurately simulating ship plume chemistry in a representative turbulent MBL flow, or whether the convergence is occurring as a consequence of the resolution of the supplied LES winds becoming comparable to that of the chemistry model. To answer this question, higher resolution (e.g. horizontal resolution $50 \times 50 \mathrm{~m}^{2}$ ) LEM simulations are necessary, which have been beyond the scope of the present study. Such simulations may reveal that more realistic ship plumes have even lower $\mathrm{OH}$ concentrations, NOx lifetimes and ozone production efficiencies than those simulated here.

In the future this modelling framework will be used to focus on the impact of different meteorological scenarios, different emission fluxes, location and ship velocities with the aim of producing a parametrisation for inclusion in CTMs. Specifically, it would be interesting to run the model with a convectively active, overturning wind circulation in either tropical or extratropical latitudes. In a convecting case, there 


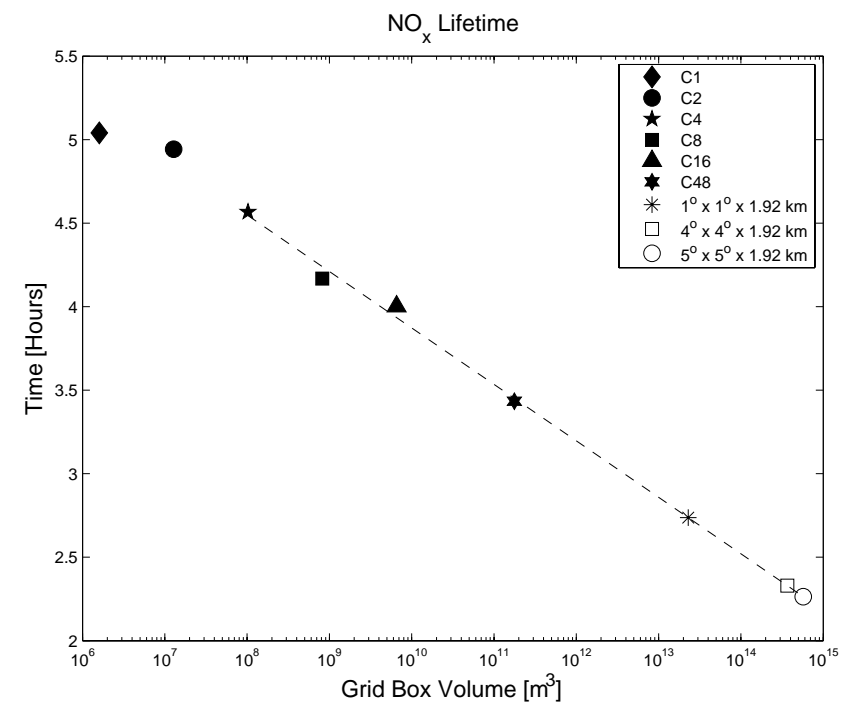

Fig. 6. Mean $\mathrm{NO}_{\mathrm{x}}$ lifetime, (defined as the ratio of domain total rate of production of $\mathrm{HNO}_{3}$ to domain total $\mathrm{NO}_{\mathrm{x}}$ ), at noon (local time) on day 2 for different resolution domains. Dashed line represents best fit to the model results $\mathrm{C} 4, \mathrm{C} 8, \mathrm{C} 16$ and $\mathrm{C} 48$. Extrapolation as in Fig. 5. For comparison, the clean model run produces a domain mean $\mathrm{NO}_{\mathrm{x}}$ lifetime of $6.4 \mathrm{~h}$ at the same time.

is likely to be increased ventilation of the boundary layer air causing the plume to disperse more rapidly which might act to decrease $\mathrm{NO}_{\mathrm{x}}$ lifetime. One would expect such a circulation to dramatically affect the plume dynamics, causing changes to the spatial pattern of dilution and perhaps affecting the "halo" of $\mathrm{OH}$ as well. Song et al. (2003) cites the high $\mathrm{OH}$ concentrations in the tropics as a reason for shorter daytime $\mathrm{NO}_{\mathrm{x}}$ lifetimes there as compared to the midlatitudes where lower $\mathrm{OH}$ concentrations give longer $\mathrm{NO}_{\mathrm{x}}$ lifetimes. Certainly, latitude and season will affect the solar flux and length of day which would have an impact on the photochemical aspects of our chemistry model.

The results presented here are an important step forward in the mapping out of the degree of uncertainty due to the neglect of ship plume dispersion and chemistry that currently plague CTM studies of the impact of $\mathrm{NO}_{\mathrm{x}}$ emission on $\mathrm{O}_{3}$ production. Our model may also be modified to study other plumes, such as those from power stations, at high resolution and without parametrization of the plume. Finally, our results suggest that better parametrisations of ship emissions in global models need to be designed using, for example, the "equivalent emissions" concept introduced in Esler (2003) or the "effective emissions" method developed by Franke et al. (2008).

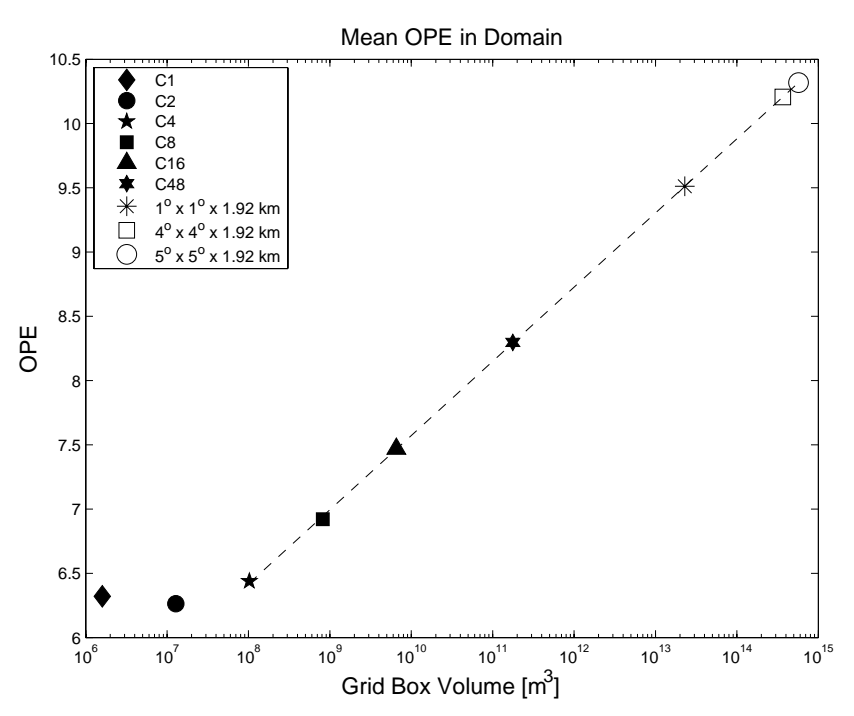

Fig. 7. Domain mean OPE at 12:30 (local) on day 2 for different resolutions. Dashed line represents best fit to the model results $\mathrm{C} 4$, C8, C16 and C48. Extrapolation as in Fig. 5. For comparison, the clean model run produces a domain mean OPE of 21.3 at the same time.

\section{Appendix A}

\section{Two-way exchange of concentrations}

To solve the advection equation

$\frac{\partial q_{n}}{\partial t}+\boldsymbol{u} \cdot \nabla q_{n}=H_{n}(\boldsymbol{q})+S_{n}$,

where the wind field is divergence-free $(\nabla \cdot \boldsymbol{u}=0)$ and where $q_{n}$ is the average concentration of the $n$-th chemical species, we calculate the concentration flux between grid boxes using the velocities at the box edges (in the $\mathrm{x}, \mathrm{y}$ and $\mathrm{z}$ directions in turn). For example, one can define the vertical flux at the bottom of box $(i, j, k) F_{i, j, k-1 / 2}$ as

$F_{i, j, k-1 / 2}=w_{i, j, k-1 / 2} \frac{\delta A \delta t}{\delta V}$

where $w_{i, j, k-1 / 2}$ is the velocity at the bottom edge of the box, $\delta A$ is the area of the base of the grid box, $\delta t$ is the advection time step and $\delta V$ is the volume of the grid box. Let $q_{i j k}^{(t)}$ be the mean concentration of a particular species in gridbox $(i, j, k)$ at time t. If, for example, $F_{i, j, k+1 / 2}>0$ and $F_{i, j, k-1 / 2}>0$ then we update the mean concentration in the vertical direction in the following way:

$q_{i j k}^{(t+\delta t)}=\left(1-F_{k+1 / 2}\right) q_{i j k}^{(t)}+F_{k-1 / 2} q_{i, j, k-1}^{(t)}$.

We coarsen the model resolution by increasing grid box volume. To advect the chemical species between the larger grid boxes we can simply average the winds along each grid box edge and calculate the fluxes with the resulting mean winds. If we choose this method, then each time we coarsen the 
(a) Vertical average without 2-way adv.

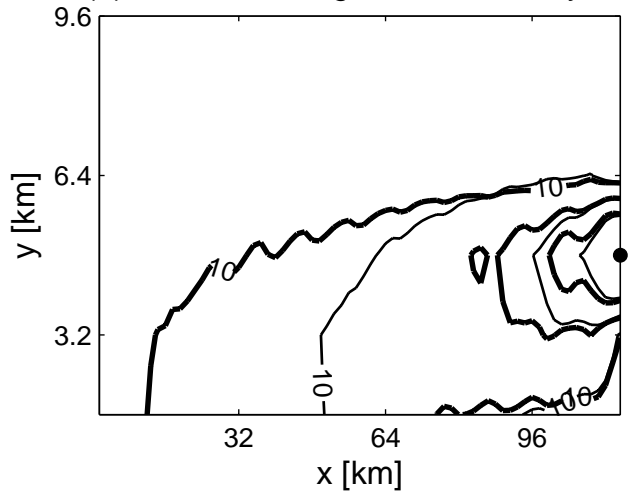

(c) Vertical average with 2-way adv.

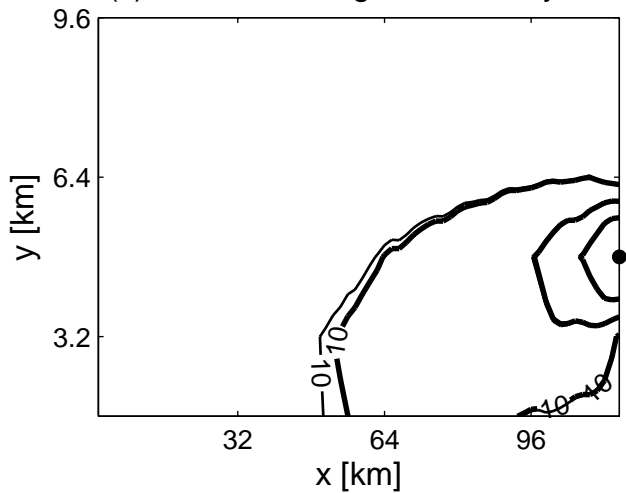

(b) Across-plume average without 2-way adv.

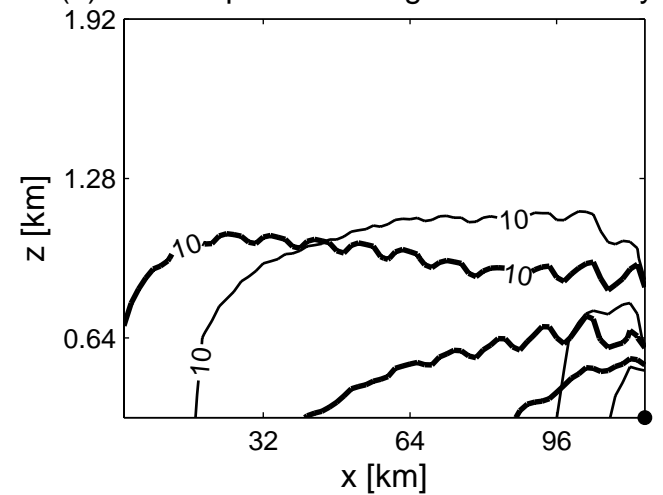

(d) Across-plume average with 2-way adv.

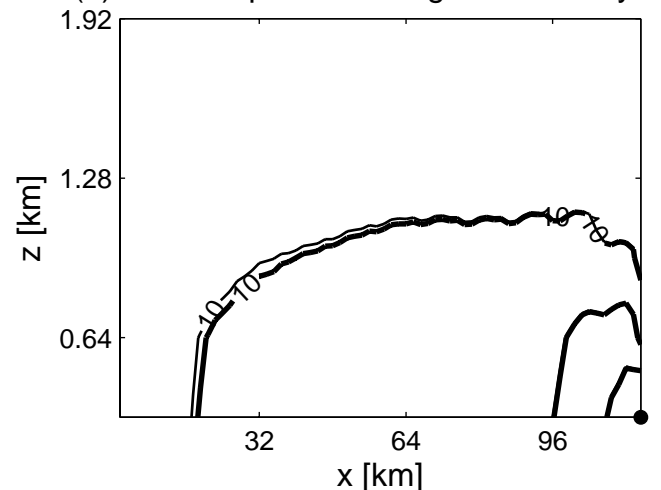

Fig. A1. Passive tracer concentration averaged over vertical (a, c) and averaged across the plume (b, d) after $18 \mathrm{~h}$. Thin lines in all panels show the model with advection at highest resolution and averaging of chemical concentrations over gridboxes equivalent to the $\mathrm{C} 8 \mathrm{coarsening}$ case. The thick lines represent the concentrations of the coarsened advection (C8) with two-way exchange turned on (c, d) and advection without the two-way exchange $(\mathrm{a}, \mathrm{b})$. Contour intervals are $10 \mathrm{ppb}$ and contour lines decrease away from the source (black dot).

model resolution we average more of the LEM wind components together thereby losing spatial variability in the wind. By averaging the wind field we stand to lose scales of motion that were originally resolved by the LEM simulation.

The method used in this study retains all of the high resolution winds and calculates a net flux into each box edge and out of each box edge at each level of coarser resolution. For this two-way flux scheme, we must calculate the total negative $F^{-}$and positive $F^{+}$fluxes at each grid box edge:

$$
\begin{aligned}
& F_{i, j, k-1 / 2}^{-}=\sum_{i, j: w_{i, j, k-1 / 2}<0} w_{i, j, k-1 / 2} \frac{\delta a \delta t}{\delta V} \\
& F_{i, j, k-1 / 2}^{+}=\sum_{i, j: w_{i, j, k-1 / 2}>0} w_{i, j, k-1 / 2} \frac{\delta a \delta t}{\delta V}
\end{aligned}
$$

where $\delta a$ is the area of the highest resolution grid box side and not the area of the larger volume box at a coarser grid resolution. Now the update for the mean concentration in box $(i, j, k)$ is

$q_{i j k}^{(t+\delta t)}=\left(1-F_{i, j, k-1 / 2}^{-}-F_{i, j, k+1 / 2}^{+}\right) q_{i j k}^{(t)}$

$$
+F_{i, j, k-1 / 2}^{+} q_{i, j, k-1}^{(t)}+F_{i, j, k+1 / 2}^{-} q_{i, j, k+1}^{(t)}
$$

regardless of the sign of the wind component.

Using the example of a passive tracer in the $\mathrm{C} 8$ resolution case, Fig. A1 demonstrates how the two-way flux scheme is superior to the wind averaging scheme as a method of coarsening the model resolution. Panels (a) and (c) show a vertically averaged plume and panels (b) and (d) show a horizontally (along-plume) averaged plume including the emission site. The black dot shows the location of the passive tracer source. The thin lines in all panels are the result of advecting at the highest resolution, but averaging the concentration over a coarse grid box volume. The top two panels (a, b) compare the high resolution advection (thin lines) to the coarsening method by averaging wind fields and performing a single flux exchange at the grid box boundary (thick lines), using the wind averaging technique. The bottom panels (c, d) compare the high resolution advection (thin lines) to the two-way exchange at the boundaries (thick lines). It is evident that the two-way exchange matches the highest resolution plume in vertical and horizontal extent much better than the wind averaging scheme. The wind averaging scheme 
causes the tracer to flatten out in the horizontal and diminishes its vertical extent. Therefore, we use the two-way exchange method to model all the degraded resolutions cases of the ship plume.

Acknowledgements. This work was funded by the Natural Environment Research Council (grant no. NE/C003713/1). The authors would like to acknowledge the reviewer M. G. Lawrence and the anonymous reviewer for their helpful comments and suggestions.

Edited by: B. N. Duncan

\section{References}

Brown, A. R.: The sensitivity of large-eddy simulations of shallow cumulus convection to resolution and subgrid model, Q. J. Roy. Meteorol. Soc., 125, 469-482, 1999.

Brown, P. N., Byrne, G. D., and Hindmarsh, A. C.: VODE: A variable coefficient ODE solver, SIAM J. Sci. Stat. Comput., 10, 1038-1051, 1989.

Chatfield, R. B. and Delaney, A. C.: Convection links biomass burning to increased tropical ozone: However, Models will tend to overpredict $\mathrm{O}_{3}$, J. Geophys. Res., 95, 18473-18488, 1990.

Chen, G., Huey, L. G., Trainer, M., Nicks, D., Corbett, J., Ryerson, T., Parrish, D., Neuman, J. A., Nowak, J., Tanner, D., Holloway, J., Brock, C., Crawford, J., Olson, J. R., Sullivan, A., Weber, R., Schauffler, S., Donnelly, S., Atlas, E., Roberts, J., Flocke, F., Hubler, G., and Fehsenfeld, F.: An investigation of the chemistry of ship emission plumes during ITCT 2002, J. Geophys. Res., 110, D10S90, doi:10.1029/2004JD005236, 2005.

Corbett, J. J. and Fischbeck, P.: Commercial Marine Emissions Inventory for EPA Category 2 and 3 Compression ignition marine engines in United States continental and inland waterways, Tech. rep., US Environmental Protection Agency, 1998.

Corbett, J. J. and Koehler, H. W.: Updated emissions from ocean shipping, J. Geophys. Res., 108, 4650, doi:10.1029/2003JD003751, 2003.

Davis, D. D., Grodzinsky, G., Kasibhatla, P., Crawford, J., Chen, G., Liu, S., Bandy, A., Thornton, D., Guan, H., and Sandholm, S.: Impact of ship emissions on marine boundary layer NOx and SO2 distributions over the Pacific basin, Geophys. Res. Lett., 28, 235-238, 2001.

Endresen, Ø., Sørgård, E., Sundet, J. K., Dalsøren, S. B., Isaksen, I. S. A., Berglen, T. F., and Gravir, G.: Emission from international sea transportation and environmental impact, J. Geophys. Res., 108(D17), 4560, doi:10.1029/2002JD002898, 2003.

Entec, UK, L.: Quantification of emissions from ships associated with ship movements between ports in the European Community, Tech. rep., European Commission, 2002.

EPA: Analysis of commercial marine vessels emissions and fuel consumption data, Tech. Rep. EPA420-R-00-002, United States Environmental Protection Agency, 2000.

Esler, J. G.: An integrated approach to mixing sensitivities in tropospheric chemistry: A basis for the parameterization of subgridscale emissions for chemistry transport models, J. Geophys. Res., 108(D20), 4632, doi:10.1029/2003JD003627, 2003.

Esler, J. G., Roelofs, G. J., Köhler, M. O., and O’Connor, F. M.: A quantitative analysis of grid-related systematic errors in oxidising capacity and ozone production rates in chemistry transport models, Atmos. Chem. Phys., 4, 1781-1795, 2004, http://www.atmos-chem-phys.net/4/1781/2004/.

Eyring, V., Kohler, H. W., Lauer, A., and Lemper, B.: Emissions from international shipping: 2 . Impact of future technologies on scenarios until 2050, J. Geophys. Res., 110, D17306, doi:10.1029/2004JD005620, 2005a.

Eyring, V., Kohler, H. W., van Aardenne, J., and Lauer, A.: Emissions from international shipping: 1 . The last 50 years, J. Geophys. Res., 110, D17305, 2005b.

Eyring, V., Stevenson, D. S., Lauer, A., Dentener, F. J., Butler, T., Collins, W. J., Ellingsen, K., Gauss, M., Hauglustaine, D. A., Isaksen, I. S. A., Lawrence, M. G., Richter, A., Rodriguez, J. M., Sanderson, M., Strahan, S. E., Sudo, K., Szopa, S., van Noije, T. P. C., and Wild, O.: Multi-model simulations of the impact of international shipping on Atmospheric Chemistry and Climate in 2000 and 2030, Atmos. Chem. Phys., 7, 757-780, 2007, http://www.atmos-chem-phys.net/7/757/2007/.

Franke, K., Eyring, V., Sander, R., Hendricks, J., Lauer, A., and Sausen, R.: Toward effective emissions of ships in global models, Meteorologische Zeitschrift, 17, 117-129, 2008.

Gray, M. E. B., Petch, J., Derbyshire, S. H., Brown, A. R., Lock, A. P., and Swann, H. A.: Version 2.3 of the Met. Office large eddy model, Tech. rep., The Met. Office, Exeter, UK, 2001.

Hewitt, C. N.: The atmospheric chemistry of sulphur and nitrogen in power station plumes, Atmos. Environ., 35, 1155-1170, 2001.

Hobbs, P. V., Garrett, T. J., Ferek, R. J., Strader, S. R., Hegg, D. A., Frick, G. M., Hoppel, W. A., Gasparovic, R. F., Russell, L. M., Johnson, D. W., O’Dowd, C., Durkee, P. A., Nielsen, K. E., and Innis, G.: Emissions from Ships with respect to Their Effects on Clouds, J. Atmos. Sci., 57, 2570-2590, 2000.

Holland, J. Z.: Comparative evaluation of some BOMEX measurements of sea surface evaporation, energy flux and stress, J. Phys. Ocean., 2, 476-486, 1972.

Holland, P. W. and Welsch, R. E.: Robust regression using iteratively reweighted least-squares, Communications in Statistics: Theory and Methods, A6, 813-827, 1977.

IPCC: Climate Change 2007: The Physical Science Basis, chap. Changes in Atmospheric Constituents and in Radiative Forcing, pp. 129-234, Cambridge University Press, 2007.

Kasibhatla, P., II, H. L., Moxim, W. J., Pandis, S. N., Corbett, J. J., Peterson, M. C., Honrath, R. E., Frost, G. J., Knapp, K., Parrish, D. D., and Ryerson, T. B.: Do emissions from ships have a significant impact on the concentrations of nitrogen oxides in the marine boundary layer?, J. Geophys. Res., 27, 2229-2232, 2000.

Lawrence, M. G. and Crutzen, P. J.: Influence of NOx emissions from ships on tropospheric photochemistry and climate, Nature, 402, 167-170, 1999.

Lawrence, M. G., Jöckel, P., and von Kuhlmann, R.: What does the global mean $\mathrm{OH}$ concentration tell us?, Atmos. Chem. Phys., 1, 37-49, 2001, http://www.atmos-chem-phys.net/1/37/2001/.

LeVeque, R. J.: Finite Volume Methods for Hyperbolic Problems, Cambridge University Press, 2002.

Liang, J. and Jacobson, M. Z.: Effects of subgrid segregation on ozone production efficiency in a chemical model, Atmos. Environ., 34, 2975-2982, 2000.

Lin, X., Trainer, M., and Liu, S. C.: On the nonlinearity of the tropospheric ozone production, J. Geophys. Res., 93(D12), 1587915888, 1988. 
Liu, Q., Kogan, Y., Lilly, D. K., Johnson, D., Innis, G. E., Durkee, P. A., and Nielsen, K. E.: Modeling of Ship Effluent Transport and Its Sensitivity to Boundary Layer Structure, J. Atmos. Sci., 57, 2779-2791, 2000.

Liu, S. C., Trainer, M., Fehsenfeld, F. C., Parrish, D. D., Williams, E. J., Fahey, D. W., Hübler, G., and Murphy, P. C.: Ozone production in the rural troposphere and the implications for regional and global ozone distributions, J. Geophys. Res., 92(D4), 41914207, 1987.

Logan, J. A.: Tropospheric Ozone: seasonal behavior, trends and anthropogenic influence, J. Geophys. Res., 90, 10463-10482, 1985.

Siebesma, A. P. and Cuijpers, J. W. M.: Evaluation of Parametric Assumptions for Shallow Cumulus Convection, J. Atmos. Sci., 52, 650-666, 1995.

Sinha, P., Hobbs, P. V., Yokelson, R. J., Christian, T. J., Kirchstetter, T. W., and Bruintjes, R.: Emissions of trace gases and particles from two ships in the southern Atlantic Ocean, Atmos. Environ., 37, 2139-2148, 2003.
Sommariva, R., Bloss, W. J., Brough, N., Carslaw, N., Flynn, M., Haggerstone, A.-L., Heard, D. E., Hopkins, J. R., Lee, J. D., Lewis, A. C., McFiggans, G., Monks, P. S., Penkett, S. A., Pilling, M. J., Plane, J. M. C., Read, K. A., Saiz-Lopez, A., Rickard, A. R., and Williams, P. I.: $\mathrm{OH}$ and $\mathrm{HO}_{2}$ chemistry during NAMBLEX: roles of oxygenates, halogen oxides and heterogeneous uptake, Atmos. Chem. Phys., 6, 1135-1153, 2006, http://www.atmos-chem-phys.net/6/1135/2006/.

Song, C. H., Chen, G., Hanna, S. R., Crawford, J., and Davis, D. D.: Dispersion and chemical evolution of ship plumes in the marine boundary layer: Investigation of $\mathrm{O} 3 / \mathrm{NO}_{y} / \mathrm{HO}_{x}$ chemistry, J. Geophys. Res., 108, 4143, doi:10.1029/2002JD002216, 2003.

Stull, R.: An Introduction to Boundary Layer Meteorology, Kluwer Academic Publishers, 1988.

von Glasow, R., Lawrence, M. G., Sander, R., and Crutzen, P. J.: Modeling the chemical effects of ship exhaust in the cloud-free marine boundary layer, Atmos. Chem. Phys., 3, 233-250, 2003, http://www.atmos-chem-phys.net/3/233/2003/. 